\title{
Generation Z and Digital Tools in Teaching Foreign Languages
}

\author{
Kateryna Remizantseva \\ Foreign Languages Department \\ Ukrainian Engineering Pedagogics Academy \\ Kharkiv, Ukraine \\ k.remizantseva1981@gmail.com \\ ORCID 0000-0002-9374-9525
}

\author{
Timur Ablyazov \\ Department of Construction Economics and \\ Housing and Utility Infrastructure \\ Saint Petersburg State University of Architecture \\ and Civil Engineering \\ Saint Petersburg, Russia \\ 3234969@mail.ru
}

\begin{abstract}
Presently, a special attention is paid to peculiarities of teaching the modern generation $\mathrm{Z}$, which will make in the nearest future already a basis of regular personnel of organizations of different spheres of activity. The issues of personnel support of production organizations appear to be one of the key elements of intensifying digital transformation of economics under conditions of forming up the sixth technological mode, since particularly the highly-skilled personnel takes on the role of condition of an effective production activity on the basis of a comprehensive use of digital technologies. Study of the foreign language under these conditions become a relevant objective in the course of training specialists of engineering trend with the aim of effecting a complex approach to forming up human resources of the country. The article gives consideration to theoretical fundamentals of using digital technologies in teaching foreign languages to the generation $Z$, gives practical examples of enhancing efficiency and effectiveness of interaction between teacher and students in the process of educational activities with the use of digital technologies. The conducted research has helped to assess the influence of a new approach to teaching foreign languages to the modern generation $Z$ on the basis of CALL (Computer Assisted Language Learning) methods on improving the process of interaction of all participants of educational process in the engineering higher educational institutions.
\end{abstract}

Keywords-Foreign languages; digital tools; generation Z; language skills; professional communication, personnel support, digital economics, digital technologies

\section{INTRODUCTION}

The modern students belong to the generation $\mathrm{Z}$, which readout has begun since 1996 and according to the experts already millions of people of this generation are entering now the labor market and this number will grow to 60 million people within two decades [1]. The generation $\mathrm{Z}$ had got accustomed to use digital technologies everywhere, which brought about a necessity of availability of digital tools in the process of education too.

The digital transformation of production activity is an indispensible condition of efficient functioning of certain industries and economics as a whole under conditions of forming up the sixth technological mode and enhancing globalization. The distribution of unified international standards of digital interaction in the framework of production activity brings about a necessity of increasing the level of knowledge of a foreign language by the specialistsengineers. The present-day engineers daily face the professional tasks related to the use of foreign languages in the context of different digital programs; moreover, this trend will get an even more wide-spread occurrence in future. At the present moment the digital programs are used more and more actively in the field of BIM modeling (Autodesk Revit, Civil 3D, ArchiCAD, Allplan) as well as such specialized programs as GPS-X, WEST, Epanet 2, Ansys CFX, etc.

A vigorous growth of technologies brings about a permanent emergence of more and more perfect technical facilities featuring a significant linguo-didactic potential. A wide spectrum of technical means, such as computer, interactive board, tablets, smartphones, projection apparatuses and many other are used currently in the practice of teaching foreign languages. All these means are consolidated under the name of "digital technologies". Dissemination of digital technologies has also influenced the methods of data submission, which is submitted more and more frequently in multimedia format. In other words, a student in the present-day world may receive information simultaneously in several forms: text, graphic, video, audio and interactive.

According to our opinion the issues of human resourcing of production organizations shall be solved presently not only through teaching specialized technical subjects with the use of digital programs, but also in the way of efficient teaching foreign languages, which can be attained through incorporation of digital tools into the process of teaching of specialists-engineers.

\section{LITERATURE REVIEW}

An incorporation of digital tools into a practice of teaching foreign languages is recognized in foreign studies as one of the basic conditions of increasing efficiency of education as well as in the professional activity to follow [2, 3]. The researcher Prensky M. has introduced the term of digital native, i.e. the "digital aborigine" to designate the generation $\mathrm{Z}$, that is, the people, who were born in "computer era" (after 1995-1996), and whose growing-up coincided with the Web 2.0 era. The representatives of this generation grew up since their childhood in a saturated information environment, and the use of information and communication technologies is natural for them penetrating all spheres of life [4]. The generation $\mathrm{Z}$ apprehends the intricate visual images 
more efficiently, since a part of brain responsible for vision is more developed with them due to a custom to perceive information via different gadgets since early childhood [5]. The study has shown that this generation prefers interactive forms of education to traditional lectures and discussions [5].

A modern student spends a greater part of his free time in Internet using it for solution of the wide spectrum of tasks, in particular, educational tasks. Prensky M. has come to a conclusion that mental processes with the representatives of digital generation go in parallel, but not in linear fashion. They use different methods of concentrating attention featuring special intensity and combination of cognitive skills [4].

So, the methods of memory functioning have changed with the modern teenagers actively using the Internet search engines: now it is aimed not at the containment of certain "content", but at memorizing a source of information, place on the Network, where it is stored. The information became readily available, which means that it is not necessary to memorize it $[6$, p. 11].

Taking into consideration the peculiarities of current generation, Peregoy \& Boyle (2012) and Nomass (2013) prove in their works that the use of special Internet applications for processing texts as well as online dictionaries helps the students master the skills of reading and writing in English quicker and more efficiently [7, 8]. It happens, first of all, because English is the main language of any Internet site.

It should be noted that a longstanding practice of using digital technologies in teaching foreign languages testifies to the fact that these teaching aids in their own right do not make the process of education more efficient. The scholars have also emphasized the fact that the students are presently aware of the capabilities of digital technologies and expect the active application thereof from education process even in humanitarian fields of science, whilst the teachers are just changing over now to the use of digital tools, since the issues of developing special methods of teaching based on the achievements of digitalization have not yet been solved to the full extent [9].

The creation of a new approach in the West European community of scholars to teaching foreign languages named CALL as abbreviation of Computer Assisted Language Learning, which means language studying with the use of computer is one of such methods. The scholars have emphasized that the students studying foreign languages with the use of CALL programs demonstrate better results than those taught according to traditional programs only (Asoodeh, 1993 [10] and Kolich, 1985 [11]). Besides, the authors note that CALL provides the teachers with a possibility of creating individual instructions, which help the students work at their own pace.

Levy, M. (1997) gives a brief description to this term in his work as a "search and exploration of computer applications when teaching and studying languages" [12]. Chapelle, C. A., Sauro, Sh. (2017) reckon that "this term is widely used for designating technologies of teaching and studying foreign languages irrespective of changing term interpretations taking place permanently" [13].

According to Davies, G. (2002) CALL is perceived as an approach to teaching and studying language, when a computer is used as an auxiliary facility for presentation, support and assessment of material that is to be studied, including normally an essential interactive element [14].

The CALL methodology has been progressing gradually over recent 30 years and passed through three stages of evolvement in its development (Fig. 1).

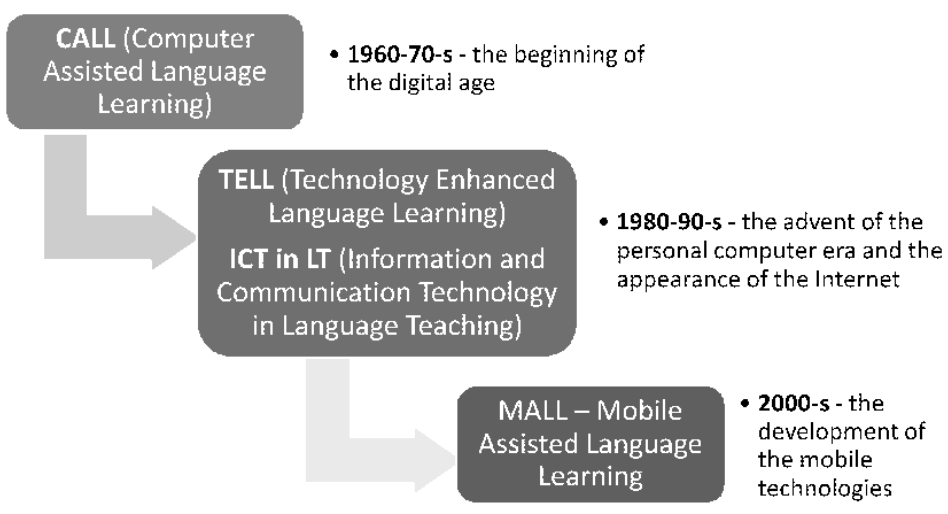

Fig. 1. Stages in setting up the methodology of CALL

The issues connected with the impact of modern information technologies on the process of teaching and learning foreign languages as well as efficient use thereof during process of teaching proper have been given consideration in a number of scientific publications of Russian scholars. M. A. Bovtenko has an opinion that the term "computer linguo-didactics" (offered by K.R. Piotrovskaya in 1991) is the most easy-to-understand meaning from the point of view of coverage of theoretical and practical aspects of using information technologies in teaching foreign languages and very soon may be superseded by the term "electronic linguo-didactics", since the information and communication technologies in teaching foreign languages gain ever wider dissemination [15].

R. K. Potapova considers that the ideas of using various sorts of technical teaching aids find the most active response in the practice of teaching foreign languages. According to her opinion the incorporation of computer technologies into teaching process can solve a number of important problems. 
First of all, it can reduce the time gap between getting to know new phenomena and control of results. Secondly, it can solve the problem of taking into account individual peculiarities of students. Thirdly, it can rectify the process of teaching students the techniques of independent work [16, p. 54].

Analyzing all the aforementioned, we arrive at the conclusion that the modern generation of students differs from their predecessors by a number of important peculiarities, which most frequently are not taken into account when compiling educational programs and selection of teaching methods. We think that wide application of multimedia and digital technologies when teaching foreign languages will provide for creation of medium required for maximum high level of competitive education as well as help more efficiently to use the cognitive peculiarities of students of engineering professions.

\section{MATERIALS AND METHODS}

The use of digital technologies when teaching foreign language takes on the role of one of the stages of enhancing efficiency of this process as well as contributes to a deeper specialization of students of technical trend due to goaloriented introduction of digital elements, which expands a spectrum of capabilities of these specialists in the framework of professional activity. A process of step-by-step introduction of digital tools when teaching foreign language is shown in Fig.
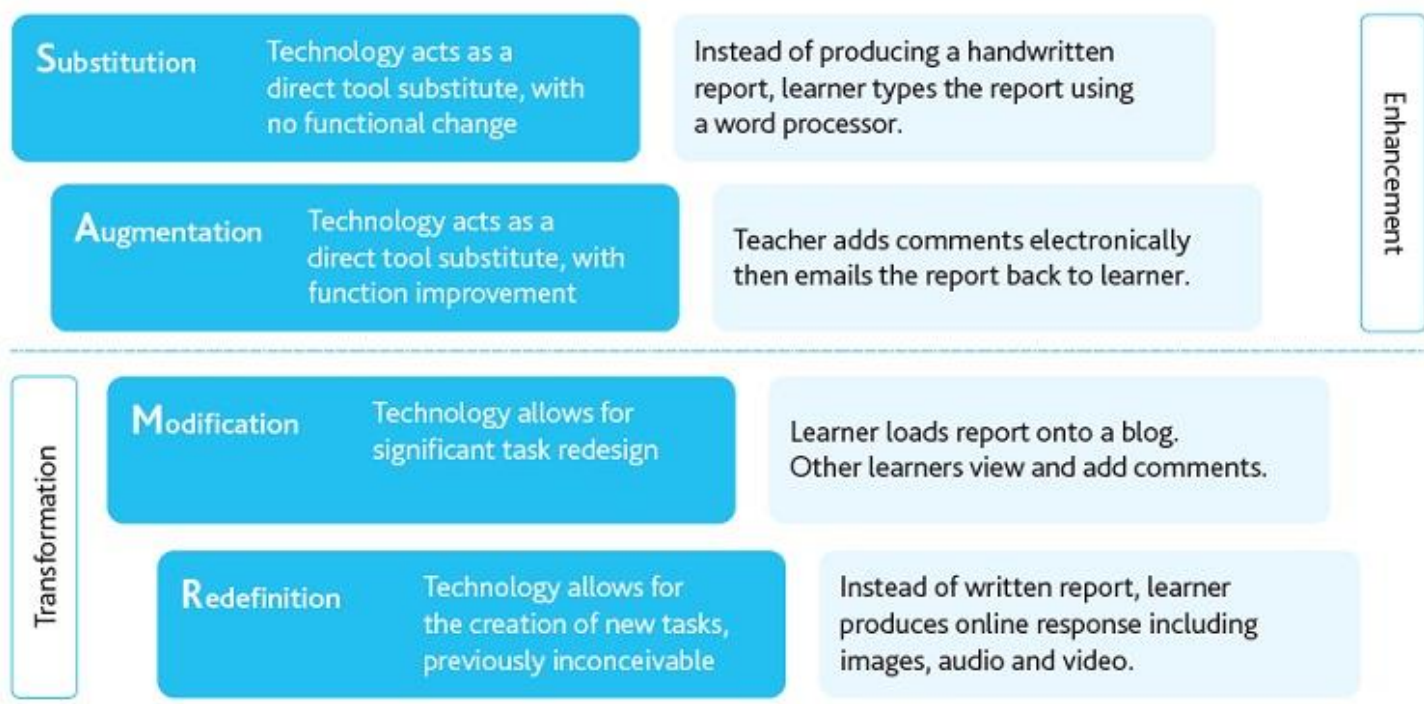

Learner loads report onto a blog.

Other learners view and add comments.

Instead of written report, learner produces online response including images, audio and video.

Fig. 2. Milestones of digital tools in the process of teaching foreihn languages [17]

The execution of the below steps will help to transform classical methods of teaching and the students will get prepared to fulfilling professional tasks at the production facility with simultaneous use of digital technologies and foreign languages.

The use of digital technologies when teaching foreign language features the following advantages [17]:

1. The digital tools help actively involve the students into a process of studying subject on the basis of interactive communication with the teacher and the group members. The tasks in digital programs can be arranged so that the students will be able to intuitively study the new lexicon and grammar, while the teacher will complement teaching with classical methods of material presentation, which in general produces a synergizing effect.

2. The use of digital technologies when studying foreign languages helps simultaneously use digital programs and apply the knowledge of foreign language already at the stage of teaching that will simplify the professional activity in specialized programs in future.

3. The digital tools of teaching foreign language open a possibility of interaction with the other groups of students, moreover, even in different regions and countries, with the aim of a deeper submergence into environment and understanding the social and cultural differences. The suchlike experience of interregional communication in the framework of education helps to apply the skills being received in practice.

4. The modern generation of students has got accustomed to use digital technologies universally; therefore, the incorporation of digital tools when teaching humanitarian sciences, foreign language, in particular, is expected by the students and will help them demonstrate their capabilities at higher level.

5. The digital technologies provide a quick feedback between the teacher and the students, which makes the process of training more efficient and goal-oriented to the demands of modern students.

The studies prove that the use of digital technologies when teaching a foreign language develops the skills of communication, extends the vocabulary, increases a degree of understanding the text [18], however, according to our opinion the study of a foreign language with the use of digital tools helps not only attain higher results in follow-up of teaching but use the knowledge in the framework of digital knowledge already at the stage of acquiring knowledge, competences and skills according to the 
program of studying a foreign language, which will come forward as an advantage when solving professional tasks in specialized digital products in the foreign language.

The computer approach to the process of teaching will be given consideration in this study as a wide spectrum of resources and tools comprising information presented in different formats on the basis of computer and mobile technologies. We consider the following technologies as the most required and resultant among the technologies, including CALL, when studying a foreign language by the students of engineering professions (Fig. 3).

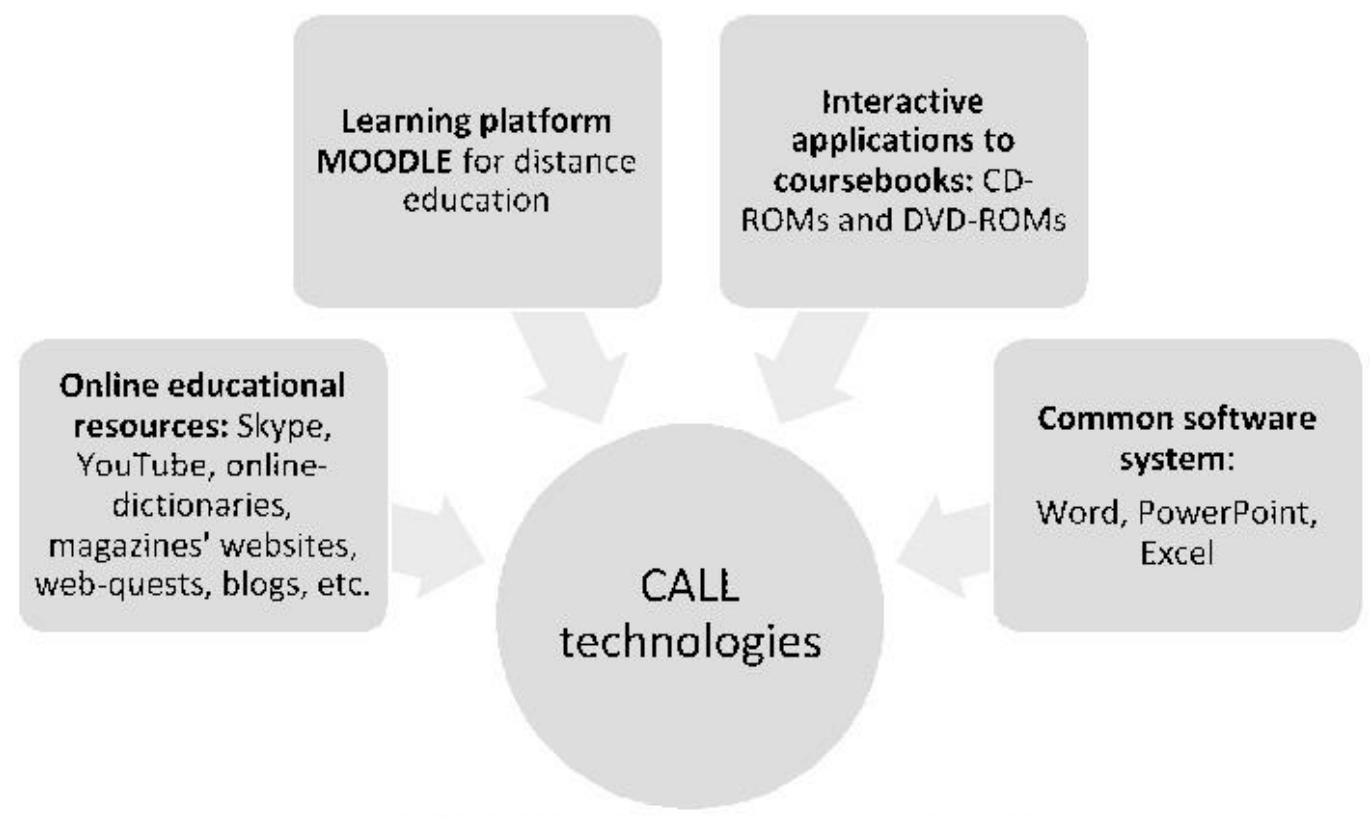

Fig. 3. CALL technologies used in the research

These technologies of learning foreign language may be used when organizing different forms of students' activity, viz: classroom work; independent work; remote teaching, as well as blended teaching, which comprise the elements of classroom and remote teaching.

It is necessary to pay special attention to the fact that blended teaching today is the most promising form of teaching foreign languages. This form of teaching under competent approach helps to combine direct communication of students with the teacher and with each other with the use of digital technologies in the course of classroom lessons with the aim of organizing independent work as well as for additional communication through electronic communication means.

We have developed a special curriculum, which included the elements of remote teaching and traditional practical lessons in the computer laboratory with the use of specifically created educational multimedia presentations. The entire course has been divided into a starting test, 12 practical lessons, independent (remote) work of students and a final test. Every practical lesson has been accompanied by a multimedia interactive presentation specifically developed by ourselves.

Among many scientific methods for conducting investigation we have decided in favor of an "experimental design", which corresponds to a method of conducting research, when the research objects (in our case these are the students of engineering professions of the $4^{\text {th }}$ course of studies) get randomly distributed into two groups: a group exposed in the framework of a program and a control group, that is, the basis for comparison.

We consider that the study of influence of digital transformation of the process of teaching a foreign language particularly for the students of engineering professions of the generation $\mathrm{Z}$ will help to improve the mechanism of human resourcing of production organizations, since digitalization encompasses presently the ever growing number of sectors of economy for forming up the digital economics, which is a global trend of the recent years.

\section{RESULTS}

In the course of four months both groups have studied the same material, though the experimental group has studied it on the basis of blended approach, which includes both traditional methods of teaching and the CALL methods. The control group has studied using traditional methodology only. Both groups had a feedback with the teacher. The lessons took place once a week for 1 hour and 20 minutes.

Prior to beginning the experiment the students had been asked a couple of questions, which concerned their previous computer working experience, staying in English-speaking countries, intention to study foreign languages and aspiration to use it in future practice. The results of this survey are demonstrated in Table 1. 
TABLE I. SURVEY OF STUDENTS BEFORE THE EXPERIMENT STARTS

\begin{tabular}{|l|l|l|}
\hline \multicolumn{3}{|c|}{ Survey of students before the experiment starts } \\
\hline \multicolumn{1}{|c|}{ Questions } & Experimental group & \multicolumn{1}{c|}{ Control group } \\
\hline Students gender & F $-14 ; \mathrm{M}-6$ & F $-13 ; \mathrm{M}-7$ \\
\hline Computer work experience & Yes $-17 ;$ No -3 & Yes $-15 ;$ No -5 \\
\hline If the English language is learnt at the students' request? & Yes $-18 ;$ No -2 & Yes $-19 ;$ No -1 \\
\hline How long has the English language already been learnt? & 3 & 3 \\
\hline The existence of language practice in an English-speaking country & 1 student (6 months) & No \\
\hline Are you going to use the English language after graduation? & Yes - 9; No -11 & Yes - 7; No -13 \\
\hline
\end{tabular}

Similarly, the students of the experimental group (before the experiment start and after its completion) have been asked, how frequently they used computer technologies for improving their knowledge of the foreign language and how much did they like using these technologies.

The results acquired before the experiment show that the study of English by means of computer software and the use of websites of social media have been approved by $95 \%$ of students. As for the online audio and video, 17 students (85\%) have indicated the same, that such websites as "YouTube" and "Skype" application have positively influenced the study of foreign language. At last, 18 students (90\%) consider that the applications for smartphones and tablets (e.g., grammar of studying English, Dictionary.com, dictionaries and thesauruses) can improve studying English, whilst 16 students $(80 \%)$ have noted that the software for text processing (Google Docs and Microsoft Word), definitely, has a positive influence on studying English.

A repeated survey already after experiment has made it possible to come to conclusions that the percentage of students considering that the use of computer technologies contributed to the improvement of studying of foreign language has increased. We have seen that 15 students $(75 \%)$ prefer to use technologies for improving their skills of speaking, reading, writing and listening, 16 students $(80 \%)$ like to study English through websites and online teaching.

Comparing the acquired survey data before experiment with the survey after experiment, we have arrived at the conclusion that the use of computer technologies at the lesson has changed the opinion of some students on the efficiency thereof for the better; especially it concerns the use of multimedia presentations. The number of students, who agree with the efficiency of using presentations during practical lessons, has increased significantly (up to $90 \%$ ).

After four months, having collected the necessary information on the basis of mentioned tools and procedures, we have conducted analysis of data and checked, how much efficient was the use of the modern digital and multimedia technologies when studying foreign languages.

We have compared the results of all tests carried out in both groups and have come to a conclusion that the level of mastering language has increased significantly in the experimental group, whilst there were no such improvements in the control group (Fig. 4).

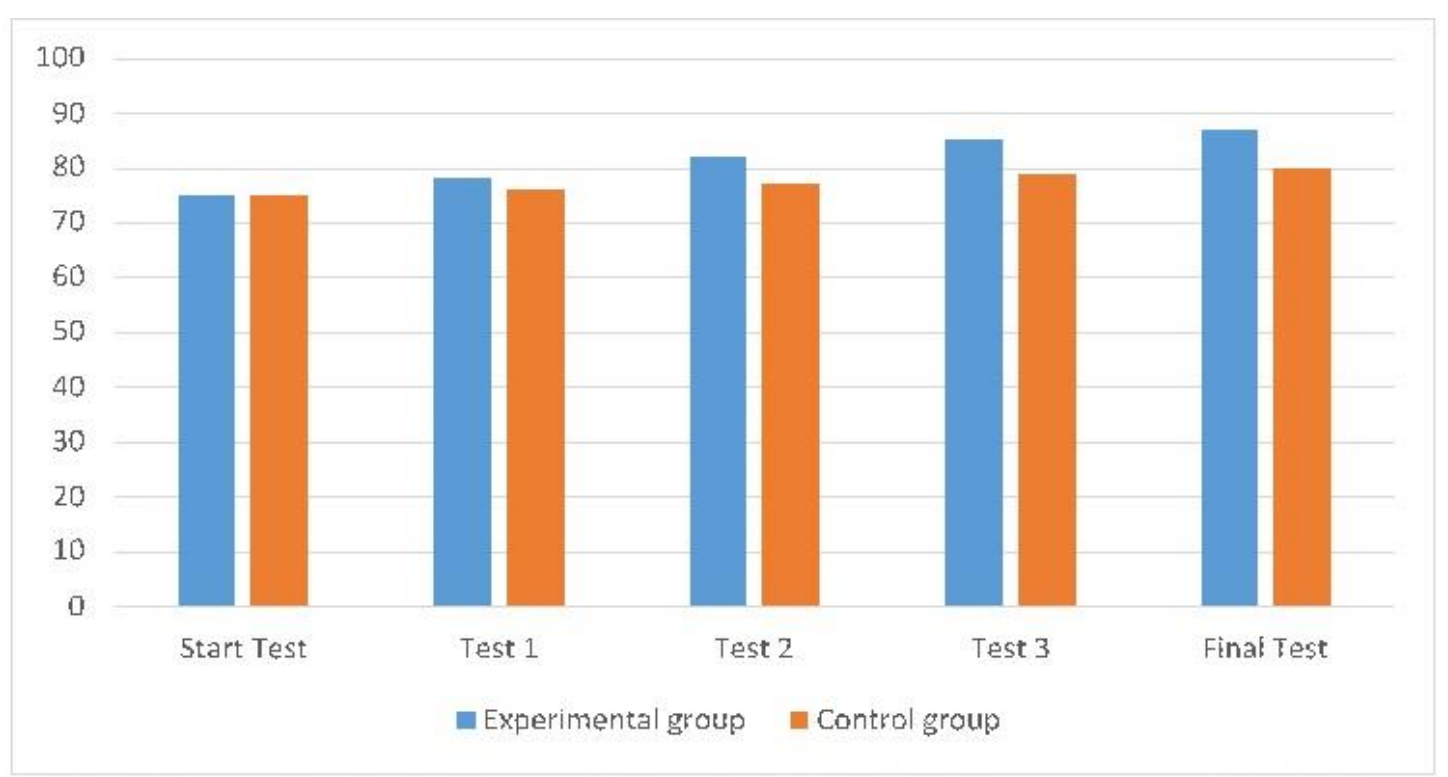

Fig. 4. Comparative charts of scores obtained by students in both groups as a result of testing

The students had different experience of work with computers and the speed of fulfilling tasks was different. Accordingly, the students having no skills of work with computer have encountered great difficulties in fulfilling tasks than the others. Hyun, E. (2005) mentioned about it in his research, when he noted that, "The students having less 
knowledge about computer as the tool for education or game, demonstrate a low level of workmanship and spend more time for purposeless clicking on images and buttons on the computer screen" [19, p. 87]. Thus, we have arrived at the conclusion that knowledge how to use computer has great influence on the motivation of students, which in turn influences their productivity in the process of education.

The second condition that will also have significant influence on the results of academic activity, with the use of CALL technologies is the gender of students. Though a greater part of our sample is represented by the girls and we do not take into account the gender difference, however, the preceding studies have shown that the male students have higher computer skills than the girls. We have found confirmation to this fact in studies of Yang \& Lester (2005), who affirm, "Studies have shown that the boys and men have more computer-related experience for solving different tasks, as well they use computer more frequently than the girls and women" [20]. Nevertheless, the students-girls have demonstrated a certain will and acquired good results, since it is not enough to have knowledge how to use computer only for studying foreign languages.

In general, the research has shown that the use of digital technologies in the course of teaching foreign languages to technical professions of the generation $\mathrm{Z}$ increases the effectiveness of studying subject. The transition to the sixth technological mode contemplates a comprehensive incorporation of digital technologies, especially in the framework of industrial sector, which requires development of the mechanism of human resourcing of production organizations. The study of foreign language is one of the elements of successful professional activity in the engineering fields; therefore, the digital instruments in the course of teaching foreign languages are to be used more intensively with the aim of developing human resources of the country in the field of technical professions.

\section{DISCUSSION}

Presently the mechanism of human resourcing of production organizations takes on the role of one of the tasks of a comprehensive digital transformation of economics, which demands improvement of educational programs of profession-oriented field-specific educational institutions in the direction of extending the practice of using digital teaching tools $[21,22]$. The education of specialists-engineers should be based on the comprehensive use of digital technologies even when studying foreign languages, since the modern requirements of professional activity include the competence of using the acquired technical knowledge and competences in the framework of specialized digital programs, which require the knowledge of the foreign language. Moreover, the production activity performed under conditions of globalization most frequently imply the interaction with the foreign partners, which also requires a high level of knowledge of foreign language by engineers.

The teaching of foreign language with the use of digital technologies has gained currency, first of all, in the framework of humanitarian professions. The most widespread digital tools when teaching foreign languages are represented in this case by the platforms of remote teaching, preparation to discussing material at the lesson through writing essay and handing it over in electronic format, personal blogging in the selected sphere in foreign language, using mobile devices and video communication for interaction with other groups and expansion of understanding of subject being studied [23].

According to our opinion the teaching of foreign languages to representatives of technical professions requires not only the application of universally accepted digital tools, such as e-mail and facilities for video communication, but also the more intensive study on the basis of specialized digital methodologies aimed at training the highly-qualified engineers capable of running professional activity under conditions of forming up digital economics.

Since the use of computers and, hence, the Internet is propagating quickly all over the world, it is necessary to encourage the teachers of foreign languages to use electronic teaching platforms as an available auxiliary educational tool to facilitate teaching foreign language. These changes take place due to a growing interest and motivation of students to use up-to-date electronic technologies. Provided the electronic teaching platforms are used correctly at the lessons, the teachers will be able to devote some portion of limited time at the practical lesson to other productive skills.

The teaching of technical professions being educated under conditions of digitalization of production activity demands incorporation of various digital tools into the process of teaching foreign language with the aim of training personnel capable of performing work in specialized digital programs as well as interact in the framework of intercountry professional community under conditions of globalization and dissemination of concept of digital economics.

\section{FINDINGS}

The generation $\mathrm{Z}$ has got accustomed to use digital tools and, moreover, it expects that the process of education will also be connected with an active use of digital tools; therefore, it is important to take into account the peculiarities of information perception by the modern students and transform the traditional approaches to teaching.

The experimental study carried out during autumn term of academic year 2018/2019 made it possible to arrive at the conclusion that the use of the CALL methodology in the course of teaching foreign language had positive results. The study testifies to the fact that a computer as a tool and electronic platform for remote teaching may help the students of engineering professions to improve their level of mastering foreign language. It has been proven in the framework of investigation that the students prefer to use digital technologies for improving their skills of speaking, reading, writing and listening comprehension, basically because they consider technologies as the most important tool of developing their creative capabilities. The teaching foreign language in engineering universities has specific peculiarities from the point of view of vocabulary, grammar and development of skills of reading, writing and listening comprehension, and the process of teaching is the most efficient in case of using digital technologies.

Thus, the incorporation of digital tools into the process of teaching foreign language to representatives of engineering professions of the generation $\mathrm{Z}$ is an efficient method of improving human resourcing of production organizations. 
The ransition to the sixth technological mode and evolvement of digital economics demand from employees the skills and competences of working with digital technologies in the process of effecting professional activity, which requires revision of classical methods of teaching in the framework of educational programs not only in specialized disciplines, but in the subjects of humanitarian trend, particularly, in foreign languages.

\section{ACKNOWLEDGMENT}

The article was prepared as part of the work on the grant of the President of the Russian Federation NSh-4028.2018.6

\section{REFERENCES}

[1] K. Kippen, A Learning Strategy for Gen Z, 2018. Retrieved from: https://www.chieflearningofficer.com/2018/09/21/a-learning-strategyfor-gen-z/

[2] M.Coccoli, A.Guercio, P. Maresca and L. Stanganelli, Smarter universities: A vision for the fast changing digital era. Journal of Visual Languages \& Computing, 25(6), 2014, pp. 1003-1011.

[3] A. Gruszczynska, G. Merchant and R. Pountney, "Digital Futures in Teacher Education": Exploring Open Approaches towards Digital Literacy. Electronic Journal of e-Learning, 11(3), 2013, pp. 193-206.

[4] M. Prensky, Digital Game-Based Learning, McGraw-Hill 2001.

[5] D. Rothman, A Tsunami of learners called Generation Z, 2016 Retrieved from: https://mdle.net/Journal/A_Tsunami_of_Learners_Called_Generation _Z.pdf

[6] G. Soldatova, E. Zotova, M. Lebesheva and V. Shlyapnikov Internet: capabilities, competences, safety. Teacher's edition for employees of general education system. Moscow: Google, 2013, p.165.

[7] B. Nomass, The impact of using technology in teaching English as a second language. English Language and Literature Studies, 3(1), 2013, pp. 111-116.

[8] S. Peregoy and O. Boyle, Reading, writing and learning in ESL: A resource book for teachers. New York: Allyn \& Bacon, 2012.

[9] C. Burnett, Shifting and Multiple Spaces in Classrooms: An Argument for Investigating Learners' Boundary-Making around Digital Networked Texts. Journal of Literacy \& Technology, 12(3), 2011.

[10] M. M. Asoodeh, Static Visuals vs. Computer Animation Used in the Development of Spatial Visualization. Unpublished doctoral dissertation, Texas A\&M University, TX, 1993.
[11] E. M. Kolich, The Effects of Computer-Assisted Vocabulary Training on the Vocabulary Achievement of Secondary School Students. Unpublished doctoral dissertation. The Pennsylvania State University, 1985.

[12] M. Levy, CALL: Context and conceptualization. Oxford: Oxford University Press, 1997.

[13] C.A. Chapelle and Sh. Sauro, The Handbook of Technology and Second Language Teaching and Learning. Wiley-Blackwell: Oxford, 2017 , p. 520.

[14] G. Davies, Article on Computer Assisted Language Learning (CALL) in the Good Practice Guide at the website of the Centre for Languages, Linguistics and Area Studies (LLAS), University of Southampton. Also available here, with updated links: LLAS CALL, 2002.

[15] M.A. Bovtenko, Information and communications technologies in teaching foreign language: creating electronic educational materials: study guide, M. A. Bovtenko. Novosibirsk: Novosibirsk State Technical University, 2008, p. 111.

[16] R.K. Potapova, New informational technologies and linguistics: study guide; Moscow State Linguistic University, Edit. 6th Moscow: LENAND, 2016, p.364.

[17] Digital technologies in the classroom. Cambridge Assessment International Education. 2017.

[18] D.V. Craig and K. B. Patten, E-literacy and literacy iPods, popular culture and language learning. International Journal of the Book, 4(1), 2007, pp. 69-74.

[19] E. Hyun, A Study of 5-to-6-year-old Children's Peer Dynamics and Dialectical Learning in a Computer-Based Technology-Rich Classroom Environment. Computers and Education. Department of Teaching, Leadership, and Curriculum Studies, Kent State University. USA, 2005. Retrieved from: www.sciencedirect.com.

[20] B. Yang and D. Lester, Sex Differences in Purchasing Textbooks Online. Computers in Human Behavior. Bennett S. Lebow College of Business, Drexel University, Philadelphia. The Richard Stockton College of New Jersey, USA, 2005. Retrieved from: www.sciencedirect.com

[21] Razinkina, E., Pankova, L., Trostinskaya, I., Pozdeeva, E., Evseeva, L., Tanova, A. Student satisfaction as an element of education quality monitoring in innovative higher education institution (2018) 33, 03043

[22] T.Kh. Allyazov and G.FShcherbina, Problems of human resourcing of construction sphere and mechanisms of solving thereof under conditions of forming up digital economics. Proceedings of VI International scientific and practical conference "PEDAGOGICAL PARALLELS”, Saint Petersburg: SPSACEU, 2018, p. 976.

[23] E. Amiri and L. Branch, A study of the application of digital technologies in teaching and learning English language and Literature. International Journal of Scientific \& Technology Research, 1(5), 2012, pp. 103-107. 